\title{
Intertextualidade na poesia brasileira contemporânea
}

\section{Intertextuality in Brazilian contemporary poetry}

\author{
Diamila Medeiros dos Santos' (UFPR)
}

Resumo: A partir da apresentação de obras de poetas brasileiros contemporâneos com dições poéticas muito diferentes entre si, como Angélica Freitas, Bruna Beber, Guilherme Gontijo Flores, Marcelo Ariel, Marcelo Montenegro, entre outros, pretendemos, no presente trabalho, destacar a questão da intertextualidade como elemento relevante dessas produções. Interessa-nos apontar o quanto esse procedimento tornou-se cada vez mais tangível, desde o Modernismo até o momento presente, forjando isso que chamamos de transitividade da poesia, isto é, a necessidade de estabelecer ligações e diálogos com outros autores e textos. Nossa base teórica incorpora autores que pensaram a teoria do texto, do hipertexto, da pós-modernidade e das produções artísticas contemporâneas, como Roland Barthes, Frederic Jameson, George Landow, Nicolas Bourriaud e Luciana di Leone.

Palavras-Chave: Poesia brasileira, Poesia contemporânea, intertextualidade.

\begin{abstract}
From the presentation of works by Brazilian contemporary poets, very different from each other, like Angélica Freitas, Bruna Beber, Guilherme Gontijo Flores, Marcelo Ariel, Marcelo Montenegro, among others, this paper aims at emphasizing the question of intertextuality as a relevant element of such productions. We are interested in pointing out how much this procedure has become more and more tangible, since the Modernism to the current moment, constructing what we call poetry's transitivity, i.e., the necessity of establishing connections and dialogues with other authors and texts. Our theoretical basis incorporates contemporary authors who have thought the theory of text, hypertext, post-modernity and contemporary artistic productions, like Roland Barthes, Frederic Jameson, George Landow, Nicolas Bourriaud and Luciana di Leone.
\end{abstract}

Keywords: Brazilian poetry, Contemporary poetry, intertextuality

\section{(...) Entre os restos, o já dito e o maldito, tortuosa construo minha}




\section{Introdução}

É possível observar que, na produção literária brasileira contemporânea, há um significativo aumento do número de publicações de poesia e também uma difusão maior dessa produção, em razão, sobretudo, do florescimento das pequenas editoras geridas, muitas vezes, pelos próprios poetas e escritores, como uma alternativa às dificuldades do mercado editorial dominado pelos grandes conglomerados de editoração e comercialização. Outro aspecto relevante neste cenário diz respeito à ampliação do acesso à internet que permite a divulgação de obras e autores, principalmente, através de blogs, suplementos culturais/literários e páginas de redes sociais. (Há, inclusive, o fenômeno mundial recente que vem sendo chamado de instapoetry - a poesia pensada para o formato do Instagram - e que tem seus desdobramentos no Brasil, gerando alguns sucessos consideráveis de vendas. Entretanto, não nos debruçaremos especificamente sobre isso no presente trabalho.) O que talvez seja mais relevante é que esses movimentos são localizáveis de maneira mais acentuada nas duas primeiras décadas do século $\mathrm{XXI}$, momento no qual as alterações econômicas, culturais e tecnológicas permitiram que esses novos mecanismos se fortalecessem.

Como resultado temos uma significativa heterogeneidade no campo das produções poéticas - apontada por alguns críticos literários, como será mostrado ao longo do artigo - que se desdobra em uma enorme dificuldade de mapeamento dessas obras, dada a já demasiadamente alardeada ausência de projeto estético comum que seja capaz de congregá-las. Entretanto, existem meios de observar algumas linhas de força que parecem, de forma geral, estar presentes em muitos poetas ao mesmo tempo. Wilberth Salgueiro, em seu artigo "Notícia da atual poesia 
brasileira - dos anos 1980 em diante" (2013), aponta alguns desses traços comuns que também considero possíveis de serem observados, como, por exemplo, um retorno da poesia subjetiva/lírica; "certa indiferença pela história, quer do Brasil, quer mundial (e, por extensão, pela participação ou pelo engajamento em causas sociais)" (p. 16); a especialização daqueles que escrevem poesia, (muitos de nossos poetas são, hoje, professores, críticos, tradutores, enfim, têm uma gama de profissões relacionadas ao universo literário).

Maria Esther Maciel, no texto "Um breve olhar sobre a poesia brasileira contemporânea" (2015), destaca como características relevantes a poesia cotidiana que se serve da banalidade do dia-a-dia enquanto matéria poética e uma significativa linhagem de escrita que "explora as mestiçagens culturais por meio de uma linguagem também híbrida e uma escrita que desafia os limites dos gêneros literários" (s.p.). Essa última guarda relações com o que o Florência Garamuño chama de "poesia fora de si", isto é, certo traço comum entre várias obras contemporâneas de poesia que "transbordam" a própria forma poética, gerando textos inclassificáveis que flertam com a prosa, e outros que extrapolam as próprias fronteiras da literatura e se aproximam das artes visuais, do cinema e da performance.

Já segundo Paulo César Andrade da Silva, no texto "Silêncio e diálogo na poesia brasileira" (2011), existe uma tendência na poesia contemporânea nomeada por ele como "antivitalista", que se caracteriza por duas facetas: uma "antidiscursiva que beira o silêncio, a outra [...] dada pela alta especialização da linguagem, que também evita a comunicação pelo seu obscurecimento (...)" (p. 3). Além disso, há também - e esse apontamento nos interessa diretamente - outra característica observada pelo professor e pesquisador que seria o diálogo estabelecido pelo eu-lírico com a tradição: "Se este diálogo é imanente à lógica do discurso da modernidade e do modernismo, tornou-se sintomático na poesia brasileira, a partir dos anos 80, transformando-se num topos significativo" (idem, p. 3).

Esse dado é também apontado por Wilberth Salgueiro em outro trabalho denominado "A poesia brasileira lida numa antologia: exercícios de solidão" (2013) que analisa a Antologia comentada da poesia brasileira do século 21 (2006), de Manuel da Costa Pinto. Segundo Salgueiro: "Na antologia, e nisso ela de fato representa uma tendência forte do cenário poético, há muitos poetas e poemas que participam desse 
jogo de citações (...)" (p. 86), constituindo intensa intertextualidade, vista por ele como um exercício de metapoesia. Essa característica é amplamente avaliada novamente em outro trabalho do autor, "A tradição visível" (2017), no qual são comentadas mais três antologias, além desta de Pinto: Roteiro da poesia brasileira anos 2000, de Marco Lucchesi (2009); Prévia poesia, de André Dick (2010); e Poesia.br, de Sergio Cohn (2013), constituindo um corpus de 141 poetas e 528 poemas, no total.

Consideramos, junto de alguns desses críticos apresentados, que essa forte presença da intertextualidade se constitui como um dado relevante em parte significativa da produção brasileira de poesia do momento presente, estabelecendose como um tipo de procedimento que se desdobra em vários usos dentro da poética de artistas distintos e que, em razão disso, tem despertado cada vez mais interesse da crítica, como é o caso do presente trabalho. Assim, gostaríamos de nos debruçar, aqui, sobre as formas através das quais podemos entender esses processos de intertextualidade em alguns poetas contemporâneos, a partir de alguns livros que consideramos interessantes, lançados nas duas primeiras décadas do século XXI.

\section{A poesia}

Obras como Metade da Arte (2003), de Marcos Siscar; A fila sem fim dos demônios descontentes (2006), de Bruna Beber; Rilke Shake (2007), de Angélica Freitas; Sanguínea (2007), de Fabiano Calixto; Tratado dos Anjos Afogados (2008), de Marcelo Ariel; A vida submarina (2009), de Ana Martins Marques; A morte de Tony Bennett (2010), de Leonardo Gandolfi; Esquimó (2010), de Fabrício Corsaletti; Tróiades - remix para o próximo milênio (2014), de Guilherme Gontijo Flores; A rede (2014) de Paula Glenadel; O livro das postagens (2016), de Carlito Azevedo; Paris não tem centro (2016), de Marília Garcia; Parsona (2017), de Adriano Scandolara; Sessão (2017), de Roy David Frankel; Forte Apache (2018), de Marcelo Montenegro; A esponja dos ossos (2018), de Marília Cecilia Brandi, apresentam o recurso recorrente da intertextualidade, isto é, fazem citação de trechos de poemas, músicas, obras de arte visuais, além de um intenso processo de referências a outros artistas (das mais diversas linguagens estéticas e de períodos históricos diferentes). 
Pensemos em algumas dessas obras. O título do livro de Bruna Beber, A fila sem fim dos demônios descontentes, foi retirado de uma pichação de rua do artista plástico Gustavo Speridião - o que é contado no fim da segunda edição do livro. Neste, encontramos poemas com títulos como "John Cage", "Saison en enfer", "um pop para Aretha Franklin", "Neil Young", "Nabokov", numa clara referência a músicos pops e eruditos - utilizando, inclusive, citações de versos de canções de Bob Dylan, da cantora francesa Camille e do próprio Neil Young -, além de uma incursão pelo mundo literário, tendo-se em vista a citação do célebre título de Arthur Rimbaud ("Saison en enfer") e a referência a Nabokov. Um dos poemas, "Rio de Janeth", utiliza os procedimentos de citação ao fazer aproximações entre figuras ilustres e lugares conhecidos do Rio de Janeiro:

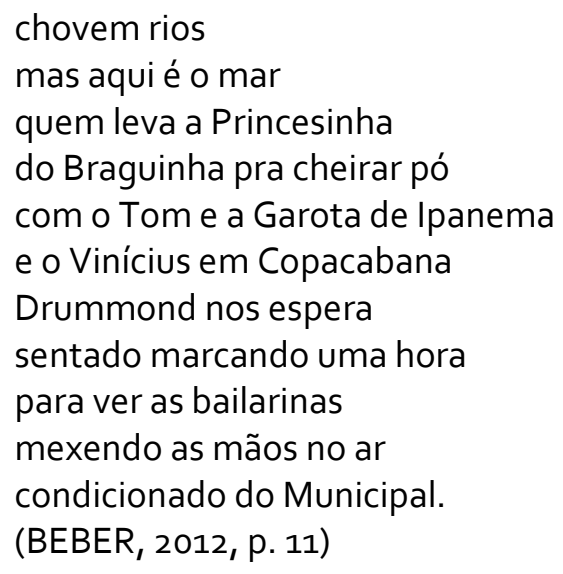

Chama a atenção no uso da intertextualidade no poema de Beber a utilização da canção popular brasileira, seja pela referência à Braguinha - Carlos Alberto Ferreira Braga (1907-2006) -, e a sua composição "Copacabana", seja pela dupla Tom Jobim (1927-1994) e Vinicius de Moraes (1913-1980), e a mais que célebre música "Garota de Ipanema". Vinícius surge no poema, entretanto, como uma referência dupla, já que é de sua autoria também um poema denominado "Copacabana" - bairro emblemático do Rio de Janeiro, no qual hoje está localizada a estátua que homenageia Carlos Drummond de Andrade (1902-1987), o poeta mineiro que eternizou a paisagem do Rio em alguns de seus versos, mas que figura ali ao lado de um de seus contos, "A Bailarina" (1981). Da mesma forma como podemos observar nas obras desses autores, no poema de Beber há um jogo constante entre as letras dos poemas e canções e as próprias paisagens da cidade. Além do deslocamento operado em relação à 
idealização que se faz dessas paisagens: através de um tom, entre irônico e debochado, "a princesinha do mar cheira pó" e a bailarina, que despertava os sonhos de uma criança no conto de Drummond, está ali guardada no ar refrigerado da sala de apresentações.

Ironia, humor, deboche são elementos igualmente trazidos pelos versos de Angélica Freitas - uma das poetas mais interessantes de sua geração e que causou grande impacto com a publicação de Um útero é do tamanho de um punho (2012). Rilke Shake, seu livro de estreia, apresenta desde o título a particularidade trocadilhesca e bem-humorada que será característica das várias referências evidentes em seu livro. Essas referências vão, assim como em Beber, do universo da música clássica ao mundo pop, citando de Stravinski ao festival Glastonbury, indo de Bela Bartók a Rita Lee e passando por Joseph Brodsky, Gertrude Stein, Alain Resnais e Elizabeth Bishop. É bem conhecido desse volume o poema "o que passou pela cabeça do violinista em que a morte acentuou a palidez ao despenhar-se com sua cabeleira negra \& seu stradivárius no grande desastre aéreo de ontem" (p. 14-15), escrito a partir de um exercício proposto por Carlito Azevedo em uma oficina de criação poética que sugeria aos participantes que escrevessem em diálogo com o poema de Jorge de Lima, "O grande desastre aéreo de ontem", de A túnica Inconsútil (1938). No poema de Angélica Freitas, a poeta utiliza a imagem do violinista que aparece no poema de Lima e nos relata os diversos pensamentos que lhe ocorreram, mas o tom do poema se modifica e, embora, se mantenha a situação trágica do acidente aéreo, a voz poética se apresenta de maneira cômica, brincando com os sons dos nomes aos quais faz referência. É possível observar também que há um intenso processo de dessacralização de alguns elementos do mundo da chamada alta cultura, desde a referência inicial a Jorge de Lima até as outras já apontadas. Isso se repete em outros poemas do livro, como o que segue abaixo:

\footnotetext{
estatuto do desmallarmento

minha senhora, tem um mallarmé em casa? você sabe quantas pessoas morrem por ano em acidentes com mallarmé?

estamos organizando uma consulta popular para banir de vez o mallarmé dos nossos lares
} 
as seleções do reader's digest fornecerão

contêineres onde embarcaremos os exemplares, no porto de santos, de volta pra frança. seja patriota, entregue seu mallarmé. olê. (FREITAS, 2007, p. 53)

Aqui, o jogo inusitado empreendido é entre o "Estatuto do Desarmamento", lei Federal do ano de 2003, e uma proposta - mais uma vez, entre irônica e debochada de "desmallarmento", ou seja, uma proposição que pretende livrar o Brasil de Stéphane Mallarmé, poeta francês dos mais tradicionalmente reconhecidos como herméticos. Outra referência presente no texto é à Revista Seleções (Reader's Digest), conhecida como uma publicação de vulgarização de conteúdo diverso, mas de leitura leve e rápida, instaurando uma clara oposição à própria ideia da poesia de Mallarmé. Levando-se em conta o tom irônico e paródico do livro como um todo, é possível que se entenda a referência à Mallarmé como uma piada com essa ideia de poesia complicada, densa, pesada. Mas, e nisso também reside parte significativa dos trabalhos que usam a intertextualidade dessa forma, é possível entender um processo que reconhece a centralidade do poeta na construção de uma tradição sobre o fazer poético, afinal, se é necessário que haja o "desmarllamento" isso significa que esse é dado recorrente, ou ao menos discernível na poesia brasileira - seja para agregar qualidades ou defeitos.

Marcelo Ariel, no Tratado dos Anjos Afogados, e em suas obras como um todo, utiliza amplamente os processos de intertextualidade com outras obras e artistas muito diferentes entre si, como Dante, Torquato Tasso, Paul Celan, Fernando Pessoa, Gilberto Mendes, entre outros. Podemos observar também que suas referências se estendem ao universo pop com citações de Miles Davis, John Coltrane, Sonic Youth, Cartola, Racionais Mc's, sem esquecer da utilização de materiais menos ortodoxos, como a carta de fundação do PCC (Primeiro Comando da Capital). Em um trabalho mais longo acerca da obra de Ariel (SANTOS, 2016), esse intenso processo de referenciação empreendido por sua obra é chamado de "pós-produção", utilizando, para tal, algumas das definições do crítico de arte francês Nicolas Bourriaud para a arte contemporânea (idem, p. 102). Na obra de Ariel, as referências se acumulam de forma quase exaustiva e compõem de maneira determinante sua dicção poética, uma 
das mais singulares dentre os poetas aqui apresentados e que, assim como nas poetas que apresentamos, constitui um forte questionamento das hierarquias não só entre arte pop e/ou popular e erudita, mas também entre o discurso literário e outros discursos, como a filosofia, a crítica literária, o cinema, a música, em um movimento facilmente reconhecível como pós-moderno, ponto ao qual retornaremos mais adiante.

O livro Tróiades, além de ser o desdobramento de um poema-site, o que em si já aponta para outro tipo de perspectiva artística e editorial, é construído, segundo Guilherme Gontijo Flores, a partir do recorte, da tradução e do remanejamento de três tragédias antigas (Troiades e Hecuba, de Eurípedes, e Troades, de Sêneca) e do aforismo 9 da obra de Walter Benjamin, Sobre o conceito de história (1940). No livro físico, em uma pequena caixa de papel, cada um desses fragmentos está no verso de uma fotografia retirada da Wikimedia Commons. Essas fotos guardam de semelhança entre si o fato de serem retratos de inúmeras tragédias vividas por diversos povos (Dresden-Alemanha bombardeada, em 1945; sobreviventes de Canudos; pessoas escravizadas na Tunísia, em 1900; crianças enforcadas na Itália, em 1923). Além disso, no site, que se mantém no ar, há uma música que toca recorrentemente "Genocide Symphonic Holocaust" (2005), de Maurizio Bianchi.

Em Sessão, Roy David Frankel utiliza trechos da sessão parlamentar que culminou com o impeachment da Presidente Dilma Rousseff, em 2016. O autor se apropria dos discursos desastrosos dos deputados e os metrifica, com o intuito de torná-los poemas, num intenso processo de apropriação do discurso do outro e utilizando um tipo de matéria poética bem pouco convencional, mas que não deixa de ser um processo intertextual.

Forte Apache (2018), de Marcelo Montenegro - poeta, músico, iluminador de teatro, roteirista de televisão e cinema - é composto de mais dois livros, Garagem Lírica (2012) e Orfanato Portátil (2003), além do livro homônimo. Todos eles trazem, como elemento formal característico, o processo de intertextualidade, destacado por Chacal, na orelha do livro: Forte apache "(...) lança mão de uma 'narrativa' cardiográfica para dar nome e sobrenome aos bois de seu paideuma pop: Tchékhov, Seinfield, Hopper, Truffaut, Fellini, Beatles, Cabral, Patti Smith, Itamar Assumpção". E, além dos nomes de diversos artistas, seriados de televisão, marcas de produtos 
presentes no interior dos poemas, há ainda, na edição, uma página final contendo os "créditos", ou seja, uma lista com os nomes das obras das quais foram retiradas algumas das citações que compõem os poemas. Ali é possível ver de Friedrich Nietzsche a Marcelo Mirisola, de Arnaut Daniel a Charles Bukowiski. Segue um dos poemas presentes no livro:

\section{Ensaios}

1.

Nelson Cavaquinho é o Ingmar Bergman do samba;

AC/DC, os James Browns do metal;

Marcelo Nova foi o Toquinho do Raul;

o seu Francisco (a duas quadras aqui de casa)

é o Shakespeare dos pastéis, Ramones

são Beatles arruaceiros; Faulkner, um pedreiro

experimental; Lou Reed é um Frank Sinatra

roto; Carver é Hopper (em formato conto);

Tom Zé é um misto de Marcel Duchamp

com Jackson do Pandeiro; Seinfeld é Homero.

2.

Beatles é uma perfeição

a que a humanidade

raramente chega.

É Tchékhov, Rilke, Pelé

e Coutinho, Nonas

Sinfonias, Ilíadas, Catherine

Deneuves, pirâmides

egípcias de três minutos.

(MONTENEGRO, 2018, p. 36)

No poema acima, é possível observar a sobreposição de universos distintos: do futebol, do rock, do samba, do sitcom, da arte de vanguarda, da literatura clássica, do cinema, que se entrelaçam e servem de medida uns para os outros, sempre pela via da comparação. Os deslocamentos operados pelo poema ficam por conta da referência ao seu Francisco, como o "Shakespeare dos pastéis" e a Faulkner como um "pedreiro experimental", ou seja, mais uma vez, universos distintos de produção se encontram e se sobrepõem.

Procedimento um pouco distinto é o utilizado por Maria Cecília Brandi: a intertextualidade aparece por meio de citações no meio dos poemas marcadas apenas pelo uso do itálico. Porém, no fim do livro, a poeta nos oferece uma lista com as obras 
utilizadas nas citações: majoritariamente de prosa da segunda metade do século XX até a atualidade, de autores como Lygia Fagundes Telles, Milan Kundera, Philip Roth, Gabriel Garcia Márquez, Raduan Nassar, entre as quais há espaço também para a citação de textos de outra natureza, como é o caso de "Peso" (1988), do escultor Richard Serra, e "Xifópagas capilares entre nós" (1997), do artista plástico Tunga. São frases que, ao serem incorporadas ao poema, sofrem quebras e rearranjos que as convertem em versos e as incorporam à ideia do poema. Segundo a poeta:

(...) Os poemas foram elaborados de duas formas: a partir de versos meus e, no processo de criação, buscando entrelaçá-los a trechos pinçados de prosa; ou partindo do impacto da leitura desses fragmentos, originalmente em prosa, para desenvolver peças autônomas, ressignificando-os e, por vezes, borrando a ideia de uma fronteira estilística. (...).

Se por um lado o procedimento apresentado não buscou se sobrepor às peculiaridades de cada poema, por outro ele acentua relações, colisões e referências que talvez interessem a alguns leitores. (BRANDI, 2018, p. 55-56)

A esses poetas, poderíamos ainda adicionar vários outros nomes como Ricardo Domeneck, Paulo Scott, Carla Diacov, Adelaide Ivánova, Rodrigo Garcia Lopes, Marcelo Sorrentino, Adriana Lisboa, Alex Simões, Cae Guimarães, Sérgio Medeiros, Alberto Pucheu, Cláudia Roquette-Pinto, Marcelo Sandmann. Poetas de diferentes gerações que iniciaram suas publicações em momentos distintos, mas que publicaram nas primeiras décadas do século XXI e que apresentam, entre seus poemas, algum tipo de intertextualidade direta (usando versos e frases de outros artistas), ou então

citação de nomes de artistas (de todos os tipos de linguagens artísticas) e até mesmo a utilização de slogans de propaganda, pichações, documentos extraliterários, postagens de redes sociais, entre outros, como matéria poética. Na maior parte dos casos, a questão da intertextualidade é relevante na própria construção de alguns dos livros desses poetas, como pudemos observar.

\section{A intertextualidade}

No percurso da poesia brasileira produzida no século $X X$, encontramos várias amostras da presença constante dos procedimentos de intertextualidade em poéticas 
muito diferentes entre si. Nomes como Oswald de Andrade (1890-1954), José Paulo Paes (1926-1998), Haroldo de Campos (1929-2003), Sebastião Uchôa Leite (19352003), Roberto Piva (1937-2010), fizeram uso desse recurso. Assim, desde a antropofagia oswaldiana até a iconoclastia de Piva, passando pelo uso mais humorístico e trocadilhesco de Paes e Leite, sem esquecer da maestria de Campos ao lidar com as citações de textos clássicos e utilizar outras línguas, podemos observar que, desde o Modernismo, a citação tem surgido nas produções de alguns importantes poetas brasileiros. Entretanto, é possível observar também que aquilo que era algo muito pontual e constituinte de um projeto muito específico, o "Movimento Antropofágico", em Oswald de Andrade, acaba por se tornar relativamente mais presente, após a década de sessenta (momento de grande revolução cultural e que instaurou o discurso da pós-modernidade), e vem se delineando até chegar ao tempo presente de maneira cada vez mais contundente.

Este movimento é também observável em outros contextos: pensemos, por exemplo, em T.S. Eliot (1888-1965) e The Waste Land (1922), seu poema mais famoso, um importante marco da poesia modernista e que, hoje, quase cem anos depois de sua publicação, persiste como paradigma de poesia feita a partir de recortes e sobreposições de outros textos, literários ou não, e de diferentes contextos culturais. Para Edmund Wilson, em O Castelo de Axel (1931): "Eliot e [Ezra] Pound fundaram, de fato, uma escola poética que depende, numa escala sem precedentes, da referência e da citação literária" (WILSON, 2004, p. 126). Escola à qual ainda se junta alguém como James Joyce (1882-1941) e seu monumental Finnegans Wake (1939), onde há uma imensa quantidade de personagens que têm relação com o desejo de Joyce de narrar a história universal, o que se dá, no Wake, não só através da reelaboração e da criação das palavras, mas também por meio da utilização de um emaranhado gigantesco de referências e citações de outras obras, formando assim a rede intertextual mais complexa da literatura ocidental.

Esse quadro amplo aponta para o quanto a noção de intertextualidade é igualmente ampla e complexa. As reflexões críticas a seu respeito são construídas através de um campo semântico que, entendidas as suas especificidades, pode se desdobrar em diversas concepções. Desde a perspectiva dialógica de Mikhail Bakhtin (1929) até os trabalhos sobre hipertexto de George Landow (1992), a apropriação de 
David Shields (2010) e a escrita não-criativa de Kenneth Goldsmith (2011), passando por Julia Kristeva (1969), Roland Barthes (1973), Antoine Compagnon (1979), Gérard Genette (1982), as várias noções de intertexto dizem respeito a procedimentos literários que ora se assemelham e ora se diferenciam, mas que, ainda assim, parecem sempre guardar uma relação entre si: o diálogo com outros textos, literários ou não.

Uma das grandes dificuldades de se abordar esse conceito diz respeito a um aspecto que hoje - depois de mais de um século de filosofia da linguagem, de teorias do texto, de análise do discurso, de psicanálise, entre muitos outros - parece-nos muito clichê: um texto é sempre o texto do outro. O que um sujeito (ou um texto) diz está sempre em relação ao que já foi dito (ou escrito), anteriormente. Segundo Barthes: "todo texto é um intertexto; outros textos estarão presentes nele, em níveis variáveis, com formas mais ou menos reconhecíveis; os textos da cultura anterior e os da cultura ambiente; todo texto é um tecido novo de citações passadas". (BARTHES, 2004, p. 275).

No entanto, saindo desse prisma mais genérico acerca da compreensão de intertexto e nos concentrando no campo da literatura, podemos notar um sem número de obras literárias construídas com certos procedimentos que, embora possam ser chamados de intertextualidade, têm especificidades que essa generalidade do termo não contempla e/ou que minimiza a complexidade desses fenômenos. Assim, trata-se de um termo cuja definição encontra, no decorrer de nossa tradição, diversos desdobramentos em outros vocábulos relacionados que variam de acordo com o tempo (histórico) no qual estão inseridos, ou seja, quando pensamos nas Vanguardas do início do século XX, conceitos como recorte e colagem estão afinados com as propostas estéticas do período, pensemos, por exemplo, no dadaísmo. Quando chegamos aos anos 2000, sob a influência das diversas mídias e, sobretudo, da internet, noções como pós-produção e hipertexto parecem ser as mais produtivas, isso sem pensar nas demandas ecológicas que colocam palavras como reciclagem na ordem do dia, não só em termos de consciência ambiental, mas também como procedimento estético. Além, é claro, de uma série de outros termos (alguns novos, outros como aproveitamento de práticas e teorias anteriores) que têm o intuito comum de melhor compreender e nomear essa utilização de textos anteriores dentro de outros textos, como por exemplo: citação, reescrita, eco, 
metatextualidade, repetição, paródia, pastiche, tessitura, arquivo, bricolagem, apropriação, fractalidade, mosaico, incorporação, diálogo, alusão, plágio, referência. Não pretendemos esgotar aqui as diferenças entre essas nomenclaturas, pois isso compreenderia um trabalho bem maior, porém, é pertinente que se tenha ideia do tamanho do espectro conceitual formado a partir da reflexão sobre intertexto. Para as reflexões realizadas aqui, o termo intertexto, compreendido de forma ampla será suficiente.

Quando pensamos especificamente na poesia produzida no Brasil, podemos notar que existem dois pontos de inflexão, mas que formam um continuum: o primeiro, na década de 6o, se dá sob a emergência daquilo que se tornou conhecido como pós-moderno, cujos desdobramentos se tornaram ainda mais característicos a partir das décadas de 1990 e 2000, com a chegada da internet e o surgimento dos fenômenos de "rede". O que esse novo momento histórico acrescenta, segundo Frederic Jameson é justamente "a abolição de algumas fronteiras ou separações essenciais, notadamente a erosão da distinção anterior entre a alta cultura e a chamada cultura de massa ou popular" (2006, p. 18-19). Jameson, ao falar da estética da sociedade de consumo pós-moderna, lembra a principal objeção feita aos conceitos de pós-modernidade: normalmente, diz-se que os aspectos gerais desse período não são "absolutamente novos, mas, sim, características abundantes no próprio modernismo ou no que eu chamo de alto modernismo" (idem, p. 40), ao que ele responde:

\footnotetext{
Devo limitar-me a sugerir que rupturas radicais entre períodos em geral não envolvem mudanças completas de conteúdo, mas, ao contrário, a reestruturação de certos elementos já dados: aspectos que em um período ou sistema anterior eram subordinados agora se tornam dominantes, e aspectos que tinham sido dominantes tornam-se agora secundários. Nesse sentido, tudo o que descrevemos aqui pode ser encontrado em períodos anteriores, notadamente dentro do próprio modernismo. Meu argumento é de que até hoje esses têm sido aspectos secundários ou menores na arte modernista, muito mais marginais que centrais, e de que temos algo novo quando eles se tornam os aspectos centrais da produção cultural. (JAMESON, 2006, p. 41)
}

Isso nos ajuda a entender, por exemplo, porque os procedimentos de citação de Eliot, Joyce e mesmo de Oswald de Andrade só vieram a se tornar uma 
característica amplamente difundida a partir da segunda metade do século XX e, sobretudo, nas décadas inicias dos séculos XXI. Trata-se de um elemento que não é de todo novo - como já enunciamos - mas que subverte mesmo essa noção da novidade como aspecto central na criação artística.

Nesse sentido, essa característica pode ser vista como um elemento enfraquecedor da poesia contemporânea, apontando para sua incapacidade de criação de novas discursividades poéticas, o que ratificaria as perspectivas apocalípticas acerca da produção artística do momento presente que a apontam como menor, em relação a momentos anteriores. Entretanto, alguns autores reconhecem nesses procedimentos as potencialidades da poesia contemporânea. Vera Toledo, em seu texto "Intertextualidade na poesia contemporânea" - escrito ainda nos anos 9o, sobre os poetas Rubens Rodrigues Torres Filho, Paulo Henriques Britto e o já mencionado Sebastião Uchôa Leite - aponta para essa "positividade" da intertextualidade, já que esta permite à poesia uma forma de se relacionar e ressignificar uma característica essencial de nosso tempo: a tendência à fragmentação dos discursos.

A intertextualidade é como reflexo de muitos sujeitos em uma manifestação individual. Em épocas de desagregação sócio-cultural é ela que confere uma possível estruturação ao estilhaçamento dos discursos. Compõe um todo feito de partes e estabelece uma leitura não linear onde a multiplicidade é que confere originalidade e caráter genuíno ao poema. Torna-se, portanto, um instrumento imprescindível no estabelecimento da poética contemporânea, devido às características desta época. (TOLEDO, 1996, p. 164)

Esse estilhaçamento da experiência contemporânea é reconhecível em vários outros discursos não só sobre a arte, mas também sobre nossas práticas sociais e culturais de forma ampla, traduzindo-se como um elemento presente na experiência da modernidade e que se tornou ainda mais presente na pós-modernidade. Roger Chartier (1998), historiador francês, aponta que, depois do século XVIII, os leitores passaram a fazer o que ele chama de leitura extensiva: realizada por um leitor que tem acesso a muitos textos ao mesmo tempo e que os lê em profusão, em oposição à intensiva, feita de forma profunda, mas concentrada em poucos textos. Quando chegamos ao mundo da internet e das facilidades de publicação essa dimensão da leitura extensiva se torna ainda mais presente, construindo o estilhaçamento dos 
textos e referências: pensemos em uma janela de navegador, na qual diversas abas se abrem para inúmeras mídias que são assimiladas continuamente.

Desse universo das leituras múltiplas, a noção de hipertexto, da forma como foi pensada por George Landow, se expande não só para uma reflexão acerca dos conteúdos online, mas como uma ideia que se debruça sobre nossos sistemas de pensamento: nós absorvemos e lidamos com uma quantidade enorme de informações que se organizam formando redes e conexões que não obedecem a classificações préconcebidas. Assim, a poesia produzida contemporaneamente parece dramatizar o tempo todo essa dimensão da rede e das conexões. Nessa poesia, Homero, os Beatles, Shakespeare, o pasteleiro da esquina, uma sessão parlamentar, o estatuto do PCC, podem ser associados na construção de uma dicção poética que deixa à vista a dimensão essencial de nossas construções discursivas e sociais, isto é, a alteridade, como demonstrado pela epígrafe do presente artigo.

Luciana di Leone, em seu Poesia e escolhas afetivas (2014), parte das noções filosóficas de afeto reelaboradas, a partir de Baruch Espinoza, por Gilles Deleuze, Félix Guattari e outros pensadores contemporâneos como Maurice Blanchot, Giorgio Agamben e Roberto Esposito, para pensar algumas características que a autora julga comuns nas poesia brasileira e argentina. Para Leone, não se reconhece em ambas nenhum tipo de projeto ou de programa, como argumentado por outros críticos. Entretanto, existe um traço destacável nessas obras denominado como um desejo de "fazer junto" ou mesmo, por oposição, de dramatizar a impossibilidade da comunidade, através dos modos de escrita de certa poesia contemporânea. Essa dimensão afetiva, tal como apontada pela autora, coaduna a noção da poesia contemporânea como um discurso que deseja representar em sua forma não só a fragmentação das referências no mundo contemporâneo, mas também a desierarquização dessas referências, o que é feito justamente através da intertextualidade, seja pela via da citação ou das epígrafes e dedicatórias dos poemas.

Célia Pedrosa, em seu texto "Poesia contemporânea: crise, mediania e transitividade" (2008), utiliza essa noção de transitividade para abordar uma característica da poesia contemporânea. Para ela: "Pensar a poesia como procedimento e acontecimento transitivos, de leitura e endereçamento, rumo ao plural e ao comum [...] parece ser a forma mais ativa de atualmente lidar com clichês 
hegemônicos ou contra-hegemônicos da vida cultural e literária". (PEDROSA, 2008, p. 49). Acreditamos que a transitividade da poesia pode ser expandida para além dos termos trazidos por Pedrosa: o intertexto, enquanto característica relevante, da maneira como mostramos aqui, se instaura não só como organização das referências e da fragmentação dos discursos, mas também como uma intenção dessas inúmeras vozes poéticas de saírem de suas próprias perspectivas, incorporando a do outro e levando o leitor em direção a essa multiplicidade discursiva. Dessa forma, esse fenômeno pode ser entendido como um fator capaz de dar à poesia contemporânea uma singularidade valorativa, à medida que permite a ela um gesto profundo de alteridade, reconfigurando a tradicional concepção presente em grande parte dos discursos críticos e teóricos da poesia como expressão de uma voz autoritária e monológica. Há assim, um redimensionamento das possibilidades da poesia através do diálogo, o que instaura outra postura ética para essa mesma produção poética.

\section{Referências Bibliográficas}

ARIEL, Marcelo. Tratado dos Anjos Afogados. Caraguatatuba-SP: LetraSelvagem, 2008.

AZEVEDO, Carlito. O livro das postagens. Rio de Janeiro: 7Letras, 2016.

BARTHES, Roland. Texto (teoria do). In: Inéditos. Vol. 1 - Teoria. Tradução: Ivone Castilho Benedetti. São Paulo: Martins, 2004. P. 261-289.

BEBER, Bruna. A fila sem fim dos demônios descontentes. Rio de Janeiro: 7 Letras, $2^{\mathrm{a}}$ edição, 2012.

BRANDI. Marília Cecília. A esponja dos ossos. Rio de Janeiro: 7Letras, 2018.

CALIXTO, Fabiano. Sanguinea. São Paulo: Ed. 34, 2007.

COHN, Sergio (org). Poesia.br. Rio de Janeiro: Azougue, 2013.

CORSALETI, Fabrício. Esquimó. São Paulo: Companhia das Letras, 2010.

CHARTIER, Roger. A ordem dos livros: leitores, autores e bibliotecas na Europa entre os séculos XIV e XVIII. Tradução de Mary Del Priore. Brasília: Editora Universidade de Brasília, 2a Edição, 1998. 
COMPAGNON, Antoine. La seconde main ou le travail de la citation. Paris, França: Éditions du Seuil, 1979.

DICK, André (org). Prévia Poesia. São Paulo: Risco, 2010.

ELIOT, T.S. Poesia. Tradução: Ivan Junqueira. Rio de Janeiro: Nova Fronteira, 2015.

FLORES, Guilherme Gontijo. Tróiades. São Paulo: Patuá, 2015.

FRANKEL, Roy David. Sessão. São Paulo: Luna Parque, 2017.

FREITAS, Angélica. Rilke Shake. São Paulo: Cosac \& Naify; Rio de Janeiro: 7Letras, 2007. . Um útero é do tamanho de um punho. São Paulo: Cosac \& Naify, 2012.

GANDOLFI, Leonardo. A morte de Tony Bennett. São Paulo: Lumme Editor, 2010.

GARAMUÑO, Florência. Frutos Estranhos: sobre a inespecificidade na estética contemporânea. Tradução de Carlos Nougué. Rio de Janeiro: Rocco, 2014.

GARCIA, Marília. Paris não tem centro. Rio de Janeiro: 7Letras, 2015.

GENETTE, Gérard. Palimpsestes - la littérature au second degré. Paris: Éditions du sevil, 1982.

GLENADEL, Paula. A rede. Coleção os Contemporâneos. Rio de Janeiro: Editora Confraria do vento, 2014 .

GOLDSMITH, Kenneth. Uncreative Writing. Nova York: Columbia University Press, 2011.

JAMESON, Frederic. A virada cultural: reflexões sobre o pós-moderno. Tradução de Carolina Araujo. Rio de Janeiro: Civilização Brasileira, 2006.

JOYCE, James. Finnegans Wake. Londres: Wordsworth Editions, 1987.

KRISTEVA, Julia. Séméiotike - Recherches pour une sémanalyse. Paris: Seuil, 1969.

LANDOW, George P. Hypertext: the convergence of contemporary critical theory and technology. Baltimore, Maryland: The Johns Hopkins University Press, 1992.

LEONE, Luciana di. Poesia e escolhas afetivas: edição e escrita na poesia contemporânea. Rio de Janeiro: Rocco, 2014.

LIMA, Jorge de. A túnica inconsútil. In: Antologia Poética: Jorge de Lima. Seleção e posfácio: Fabio de Souza Andrade. São Paulo: Cosac Naify, 2014. 
MACIEL, Maria Esther. Um breve olhar sobre a poesia brasileira contemporânea. Pessoa - revista de literatura lusófona, v. 1, p. 1-1, 2015. Disponível em: $<$ http://etudeslusophonesparis4.blogspot.com/2015/04/poesia-brasileiracontemporanea.html> (Consultado em og de setembro de 2018).

MARQUES, Ana Martins. A sereia e o centauro. Revista Piauí, n ${ }^{\circ} 100,2015$, s.p. Disponível em: <https://piaui.folha.vol.com.br/materia/a-sereia-e-o-centauro/> (Consultado em og de setembro de 2018).

A vida submarina. Belo Horizonte: Scriptum, 2009.

MONTENEGRO, Marcelo. Forte Apache. São Paulo: Companhia das Letras, 2018.

PEDROSA, Célia. Poesia contemporânea: crise, mediania e transitividade. In: PEDROSA, C.; ALVES, I. (org.). Subjetividades em devir. Rio de Janeiro: 7 Letras, 2008, p. 41-49.

PINTO, Manuel da Costa. Antologia Comentada da poesia brasileira do século 21. São Paulo: Publifolha, 2006.

SALGUEIRO, Wilberth. Notícia da atual poesia brasileira - dos anos 1980 em diante. $O$ eixo e a roda, Vol. 22, $\mathrm{n}^{\circ}$ 2, 2013, p. 15-38.

A poesia brasileira lida numa antologia: exercícios de solidão. Revista Texto Poético, Vol. 15, $2^{\circ}$ semestre de 2013, p. 79-108.

A tradição visível. In:

ALVES, Ida; YOKOZAWA, Solange (org.). Poesia contemporânea e tradição: Brasil \& Portugal, 2017, p. 146-159.

SAMOYAULT, Tiphaine. A intertextualidade. Tradução: Sandra Nitrini. São Paulo: Aderaldo \& Rothschild, 2008.

SANTOS, Diamila Medeiros dos. Brutalidade, pós-produção, névoa: um comentário sobre a poesia de Marcelo Ariel. 2016. 144 f. Dissertação (Mestrado em Letras). Programa de Pós-Graduação em Letras da Universidade Federal do Paraná. Disponível em: <http://www.prppg.ufpr.br/siga/visitante/trabalhoConclusaoWS?idpessoal=278go\&id programa $=40001016016 \mathrm{P} 7 \&$ anobase $=2016 \&$ idtc $=1295$ ) (Consultado em 07 de setembro de 2018).

SCANDOLARA, Adriano. Parsona. Curitiba: Kotter Editorial, 2017.

SHIELDS, David. Reality Hunger - a manifesto. Nova York: Vintage Books, 2011.

SILVA, Paulo César Andrade. Silêncio e diálogo na poesia brasileira. Cadernos de Semiótica Aplicada. Araraquara, Vol 9, n², 2011, p. 1-17. 
SISCAR, Marcos. Metade da arte. São Paulo: Cosac \& Naify, 2003.

TOLEDO, Vera Márcia Soares. Intertextualidade na poesia brasileira contemporânea. Notas sobre o uso de recursos intertextuais na poesia brasileira atual. Revista Contexto - UFES. Ano V, n. 4, (1996): 155-166.

WILSON, Edmund. O Castelo de Axel - Estudos sobre Literatura Imaginativa de 1870 a 1930. Tradução: José Paulo Paes. São Paulo: Companhias das Letras, 2004.

' Diamila Medeiros dos Santos - Doutora em Letras (2020) pela Universidade Federal do Paraná (UFPR) com tese sobre poesia brasileira contemporânea. Tem mestrado em Letras, Bacharelado em Estudos Literários e Licenciatura em Francês pela mesma instituição. Desenvolve pesquisas na área de estudos literários, atuando principalmente nos seguintes temas: literatura brasileira, poesia brasileira, poesia francesa, ensino de literatura e mediação de leitura.

medeiros.diamila@gmail.com 